235 SUDDEN INFANT DEATH SYNDROME (SIDS) AMONG INFANTS OF DRUG DEPENDENT MOTHERS (IDDM). Cleofe J. Chavez, Joan Obstet./Gynec., Wayne State Univ. \& Hutzel Hospital, Detroit, MI Sudden unexpected death among IDDM is a major medical problem. Our experience at Hutzel Hospital shows a very high incidence of SIDS among the IDDM $(17 / 1000)$. A retrospective study of IDDM was performed to determine if any neonatal factors exist which may predispose to sudden unexpected infant death.

RESULTS: From $9 / 74$ to $9 / 77$ a total of 637 fullterm IDDM weighing at least $2268 \mathrm{~g}$ were delivered. Using the criteria previously reported, the severity of neonatal drug withdrawal was assessed: $89 \%(564 / 637)$ had minor to $\mathrm{mild}$ (MM) and $12 \%(73 / 637)$ moderate to severe (MS) withdrawa1. Two percent $(14 / 637)$ were later reported to have died of SIDS. A significant $1 \mathrm{y}$ higher number of infants with MS $(6 / 73)$ died of SIDS compared to those with MM withdrawal $(8 / 564), x^{2}=9.060,0<0.01$. Those who died had no significant med ical problems during the neonatal perfod. All died between 4-16 weeks of age: $57 \%$ in Winter, $21 \%$ in Summer and $21 \%$ in the Fall. CONCLUSION: 1) The frequency of SIDS is higher among IDDM compared to the general population. 2) A significantly higher incidence of infants with MS withdrawal died from SIDS compared to those who had lesser degrees of withdrawa1. 3) Since there is a correlation between maternal methadone dose and severity of neohatal withdrawal (J Pediat, Apri1/76), the use of low methadone dosage during pregnancy is strongly recommended.

\section{PHARMACOKINETICS OF AMIKACIN IN CHILDREN WITH MALIG-}

236 J. Culbert, Willijam Kramer, Steve Kohi, Stuart Feld man, Jan van Eys (Spon. by R. Rodney Howell). The Univ. of Tex Med. School, Dept. Inf. Dis. \& Pediatr., The Univ. of Tex. Sys tem Canc. Ctr., Dept. Pediatr., The Univ. of Houston, Dept. Pharm., Houston, Texas.

Amikacin is an aminoglycoside antibiotic that is effective against gram negative bacilli which are resistant to other aminoglycoside antibiotics. Pharmacokinetic data of amikacin in pediatric patients are scant. The pharmacokinetics of in pediatric patients are scant. The pharmacokinetics of 14 years of age) with malignancies. Children receiving 15 or $20 \mathrm{mg} / \mathrm{kg} / 24 \mathrm{hr}$ administered every 8 to 6 hours, respectively had peak serum concentrations of $16.9 \pm 3.67 \mu \mathrm{g} / \mathrm{ml}$ (mean \pm SD) at the end of a one hour infusion. Six and 8 hour serum concentrations were $1.27 \pm 1.26$ and $0.64 \pm 0.92 \mu \mathrm{g} / \mathrm{ml}$, respectively. The $t \frac{1}{2}$ was $78 \pm 43.8$ minutes and the total clearance was $133 \pm 43 \mathrm{ml} / \mathrm{min} / 1.73$ $78 \pm 43.8$ minutes and the total clearance was $133 \pm 43 \mathrm{ml} / \mathrm{min} / 1.73$
$\mathrm{~m}^{2}$. The mean volume of distribution was $0.26 \pm 0.08 \mathrm{l} / \mathrm{kg}$. No $\mathrm{m}^{2}$. The mean volume of a A $9 \%$ inactivation of amikacin occurred when incubated in normal donor sera at $37^{\circ} \mathrm{C}$ for 72 hours with varying concentrations of ticarcillin. Due to the rapid renal clearance and short half life of amikacin in these children, the currently recommended dose of amikacin should be increased and the frequency of administration shortened.

\section{7}

\section{PLACENT AL TRANSFER OF MORPHINE IN THE EWE} Martin S. Cohen, Abraham M. Rudolph and Kenneth L. Melmon Pediatrics and Medicine, San Francisco.

Maternal and fetal plasma clearance of morphine(M) as well as maternal to fetal and fetal to maternal clearance of $M$ were studied in 4 chron ically catheterized pregnant ewes and their fetuses. Morphine sulfate was infused into the ewes at a rate of $0.329 \pm 0.06 \mathrm{mg} / \mathrm{min}$ for 4 hours Arterial plasma $M$ concentrations were measured by radioimmunoassay at specific intervals in the ewes and fetuses during and after the infusion. Twenty-four hours later, $M$ was infused into the fetuses at a rate of $0.054 \pm 0.013 \mathrm{mg} / \mathrm{min}$ for 4 hours and respective $M$ concentrations meas ured. During the maternal infusion, the steady state plasma concentration of $M$ achieved by the ewes was $97.8 \pm 17.6 \mathrm{ng} / \mathrm{mi}$ and by the fetuses $14.7 \pm 8.4 \mathrm{ng} / \mathrm{ml}$. During the fetal infusion, the steady state plasma concentration of $M$ achieved by the fetuses was $141.2 \pm 63.4 \mathrm{ng} / \mathrm{ml}$ and by the $\mathrm{ml} / \mathrm{min}$ and in the fetuses was $425 \pm 150 \mathrm{ml} / \mathrm{min}$. The maternal to fetal clearance of $M$ was $65.1 \pm 40.4 \mathrm{ml} / \mathrm{min}$. The fetal to maternal clearance of $M$ was $84.4 \pm 33.2 \mathrm{ml} / \mathrm{min}$. These results indicate that only $20.0 \pm 5.0 \%$ of the total fetal clearance can be accounted for by fetal to maternal clearance. This suggests that maternal clearance of morphine is not the major route of elimination for the fetus. It cannot be assumed, however, that the remaining clearance is exclusively fetal metabolism since renal excretion of unchanged drug and placental metabolism were not determined.
238

RESPONSES TO MORPHINE IN THE PREGNANT EWE Martin S. Cohen, Abraham M.Rudolph and Kenneth L. Melmon Pediatrics and Medicine, San Francisco.

It is not known whether the fetus can develop opiate dependence (OD) as a primary,drug-related effect of maternal to fetal transfer of morphine sulfate(MS) or whether fetal responses are related to altered maternal physiology. Four non-pregnant and 4 pregnant ewes were studied. A continuous intravenous (IV)infusion of MS was given to the ewes(10mg/ $\mathrm{kg} / 24$ hours). The response was measured to IV administration of naloxone $(\mathrm{N}), 0.04 \mathrm{mg} / \mathrm{kg}$ to the ewes and $0.02 \mathrm{mg} / \mathrm{kg}$-estimated weight to the fetuses. As early as 24 hours after beginning the MS infusion, N increased arterial blood pressure (ABP) in the non-pregnant ewes (mean $\pm S E$ ): sys $\pm 2.7(p<.001)$; and in pregnant ewes: systolic $114.2 \pm 2.6$ to $140.7 \pm 3.0$ $(p<.001)$. All animals demonstrated "withdrawal" responses. There was ( $\mathrm{p}<.001)$. All animals demonstrated "withdrawal" responses. There was tolic $63.9 \pm 2.1$ to $75.0 \pm 4.2$ ( $p<.001)$; diastolic $36.8 \pm 2.0$ to $41.8 \pm 2.7$ $(p<.001)$. In contrast to the mothers, there was a fall in fetal heart rate: meconium a $\pm 5\left(p<.001\right.$ ) and $\mathrm{pO}_{2} 24.4 \pm 0.81$ to $22.2 \pm 1.04$ ( $2<.05$ ) and duced similar significant changes plus arterial pH fell from $7.39 \pm 0.01$ to $7.35 \pm 0.02(p<.05)$. In alamb born after 14 days of MS infusion to the ew $\mathrm{N}$ produced cardiovascular responses similar to those before birth, and the "withdrawal" responses seen in the ewes. MS, therefore, crosses the placenta and has a primary drug effect in the fetus. In addition, the fetus has a unique pharmacologic response to $\mathrm{N}$ after exposure to MS. This suggests the potential for development of $O D$ in the fetus as a primary,

239 DECREASE IN $\alpha$ - ADRENERGIC BINDING SITES IN NEWBORN 239 PLATELETS: CAUSE OF ABNORMAL RESPONSE TO EPINEPHRINE? Investigation Service, Fitzsimons Army Medical Center, Denver, Co Platelets of newborn infants show diminished aggregation to epinephrine. Because epinephrine-induced aggregation is an $\alpha$-adrehergic receptor-mediated response, we considered the possibility that platelets of newborn infants possess fewer epinephrine bind ing sites than do those of adults. Using the specific and potent $\alpha$ - adrenergic antagonist, $\left[{ }^{3} \mathrm{H}\right]$ dihydroergocrypt ine (DHE), we compared the specific DHE binding to $\alpha$-adrenergic binding sites in platelets from paired maternal and cord blood samples. Platelets were washed twice with buffer (Tris-HCl, $0.05 \mathrm{M}, \mathrm{pH} 7.35 ; \mathrm{NaCl}$, $0.15 \mathrm{M}$ EDTA, $0.02 \mathrm{M}$ ) and incubated with either $5 \mathrm{nM}\left[{ }^{3} \mathrm{H}\right]$ OHE or $5 \mathrm{nM}\left[{ }^{3} \mathrm{H}\right]$ DHE $+1 \mathrm{mM}$ epinephrine. After $18 \mathrm{~min}$, the reaction was stopped by adding excess buffer and the platelets were recovered by filtering on Whatman GFC glass fiber filters. Maternal platelets were found to bind approximately two-fold more $\left[{ }^{3} y\right]$ DHE than platelets from cord blood $(2.06$ vs. 1.11 femtomoles/10 platelets; $p<0.01)$. Since maternal and cord blood platelets are the same size, it appears that newborn platelets have fewer binding sites for epinephrine than maternal platelets. The above data is cons istent with the hypothesis that platelets from newborns have a) diminished aggregation response to epinephrine secondary to decreased numbers of receptors and b) a-adrenergic receptors that are either down regulated or not fully developed.

240

INTRAVENOUS GENTAMICIN PHARMACOKINETICS IN THE SMALL PRETERM INFANT. Will iam F. Coyer, George E. Wesbey, Katherine L. Cech, John A. Robinson, Loyola Univ. Stritch Sch. of Med., Depts.

Gentamicin (G) is an aminoglycoside frequentiy used in the treatment of neonatal sepsis and meningitis. This study reports for the first time the sequential pharmacokinetics of a constant rate one hour intravenous $G$ infusion in 60 small preterm infants during the first week of use. Using a microbiologic technique, the serum $G$ concentration (level) was measured before the

$2.5 \mathrm{mg} / \mathrm{kg} \mathrm{G}$ infusion and $1,2,4,8$, and 12 hours after the infusion was started. Mean birthweight and gestational age were 1365 grams $(700-2000)$ and 30.5 weeks $(24-36)$.

Potentially toxic trough and peak levels were observed in some cases along with a markedly prolonged half life $\left(t^{1} / 2\right)$. The peak, 2 hour ( $\mathrm{hr}$ ), and $12 \mathrm{hr}$ (trough) levels were 8.25 (1.7Drug accumulation was documented. Increasing peak levels were associated with increased trough levels and decreased volume of distribution $\left(V_{0}\right)$. Trough levels increased as dose and day of treatment increased and as $V_{D}$ decreased. Drug disposition was very rapid during the first 4 hrs and slower during the last 8

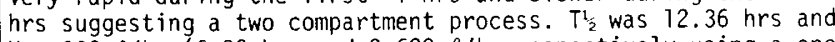
$V_{D} .802 \mathrm{l} / \mathrm{kg}(6.82 \mathrm{hrs}$ and $0.629 \mathrm{l} / \mathrm{kg}$ respectively using a one compartment model). Biweekly monitoring of trough and peak leve is necessary to avoid peak levels $>12 \mu \mathrm{g} / \mathrm{ml}$ and trough levels $>2 \mu \mathrm{g} / \mathrm{ml}$ while maintaining therapeutic levels of $4-5 \mu \mathrm{g} / \mathrm{ml}$. 